\title{
Susceptible Factors of Type-2 Diabetes in a Population of Bangladesh
}

\author{
Afsana Al Sharmin ${ }^{1}$, Munima Haque ${ }^{2, *}$ \\ ${ }^{1}$ Faculty of Applied Statistics, East West University, Bangladesh \\ ${ }^{2}$ Faculty of Electrical and Electronic Engineering, School of Science and Engineering, Southeast University, Bangladesh
}

Copyright $(\mathcal{C} 2016$ by authors, all rights reserved. Authors agree that this article remains permanently open access under the terms of the Creative Commons Attribution License 4.0 International License

\begin{abstract}
Diabetes is a buzzing word nowadays in Bangladesh as well as the world. The prevalence and incidence of type-2 diabetics is also increasing in Bangladesh. Secondary data is used in this study. It is anticipated that most patients will fall in the age range of 20-75 years. All patients, who are newly detected diabetes patients, from the year of 2012 of the BIRDEM General hospital in Bangladesh are requested to fill up a form of the Patients History Sheet. The study use bivariate analysis and a multiple regression analysis considering fifteen risk factors as covariates controlling one by one and two hours before fasting blood glucose of type-2 diabetic patients as a response variable. After controlling one by one fifteen risk factors, it is examined that there is relationship between age and type-2 diabetes. Moreover, fifteen models are considered by controlling individual outcomes to find out the confounding factors. Physical activities, occupation, family history of diabetic patients, Systolic Blood Pressure (SBP) $(>140 \mathrm{~mm} \mathrm{Hg})$, and Diastolic Blood Pressure (DBP) $(<70$ $\mathrm{mm} \mathrm{Hg}$ ) are confounders for the association of diabetes and age among Bangladeshis. None of the model showed the significant effect of sex, marital status, number of family members and smoking status on the relationship.
\end{abstract}

Keywords Risk Factors, Fasting Blood Glucose, Controlling Covariates, Confounding Factors

\section{Introduction}

In 2010, the International Diabetes Federation (IDF) estimated that 5.7 million $(6.1 \%)$ and 6.7 million $(7.1 \%)$ of people living in Bangladesh is suffering from diabetes and impaired glucose tolerance (IGT) respectively. It is indicated that the prevalence of diabetes in Bangladesh in populations aged 20-79 years is $6.6 \%$. By 2030 , that number of diabetic population is expected to rise to 11.1 million. This explosion in diabetes prevalence will place Bangladesh among the top seven countries in terms of the number of people living with diabetes in 2030. [1] Evidence suggests that type-2 diabetes can effectively be prevented. Recent research has shown that about $65 \%$ of type- 2 diabetes can be prevented by adopting appropriate life style i.e. increasing physical activity and preventing obesity in Europe and America. Type- 2 diabetes is associated with modifiable (body weight, exercise, diet) and non modifiable (heredity, aging) risk factors. Modifiable risk factors reported to be associated with type-2 diabetes are being overweight, [2-5] low physical activity, [6-8] high dietary fat intake, [9-11] and low fiber intake. [12,13]

There are top 7 Risk Factors for type-2 Diabetes. The number one risk factor for type-2 diabetes is obesity; others are Sedentary Lifestyle, Unhealthy Eating Habits, Family History and Genetics, Increased Age, High Blood Pressure and High Cholesterol, History of Gestational Diabetes. [14] Diabetes is known to be associated with multiple CHD risk factors, including hypertension, dyslipidemia, and abnormalities in hemostasis and cardiac function. [15] All of these are most consistent risk factor of diabetes. [2, 3][16-20] In addition, Area of residence (Urban/Rural) has been considered as a risk factor. [21, 22] Besides these risk factors, another one is Economic status, e.g. higher family income had significantly higher prevalence of type- 2 diabetes than that with lower income. [20, 21][23-25]

Though in these studies an interaction was found with high income family while in another study it was not, where findings suggest type-2 diabetes may be quite common in Mexican-American youths and adults from a lower than from a higher socioeconomic status. [26-29] Similarly, Sex is another risk factor where in one study; females are more affected than males. [29,30] This finding is in accord with some findings, while it differs with others, e.g. the prevalence of diabetes is higher in men than women. [22][24] For inconsistencies results it is obligated to re-examine these factors, i.e. further investigation of whether men or women are vulnerable is required. Furthermore, Cigarette smoking may be an independent, modifiable risk factor for noninsulin-dependent diabetes mellitus. [31,32] Apart from cigarettes, however, few published studies have investigated 
in regards to Education level, [33] Occupation [30] as susceptible factors.

As the risk factors for type 2 diabetes are likely to differ in different population and places; [34] therefore, considering above scenario, it is important to address these issues and to determine the risk factors of various parameters affecting diabetes in Bangladesh. In fact, our study will suggest the possible reasons, i.e. risk factors for the high incidence of diabetes among Bangladeshis. In the literature of international and local studies, it has been shown that couple of risk factors are associated with the occurrence of type-2 diabetes, and we would like to do further investigation about other risk factors which are still not explicitly quantitatively studied. Consequently, the findings of this research will open the new avenues in diabetes prevention for all individuals at risk through the identification of risk factors, which is essential to the successful implementation of primary prevention programs.

\section{Materials and Methods}

The Study is conducted on the base of data which have been collected form of the Patients History Sheet record. All patients from the year of 2012 of the BIRDEM GENERAL HOSPITAL in Bangladesh were requested to fill up a form of the Patients History Sheet. Participants are included in the study if they are diabetic patients. The analysis of this paper comprises the information of 15095 diabetes patients aged 20-79.

Initially it was anticipated that most patients would fall in the age range of 20-79 years. Data were collected from programmers within the Instructional Technology Integration and Development section under the Division of Instructional Innovation and Assessment.

For the analysis, some characteristics of diabetes patients, i.e. sex (male, female), age in years $(<31,31-50$ and $50+$ years), marital status (yes, no ), area of residence (urban, rural), education level $(<\mathrm{SSC}, \mathrm{SSC} / \mathrm{HSC} /$ equivalent, graduate/higher), occupation (HW, employed, unemployed), patient's body mass index (BMI) $(<18.5,18.5-24.99$, 25.0-29.99 and 30+ kg/m2), No of family members (1-4, > 4), Family expenses i.e. Economic status(rich, middle class, poor), Smoking habit (yes, no), past family history about Diabetes (no, yes), Diastolic Blood Pressure (DBP) $(<70$. $70-90,>90)$, Systolic Blood Pressure (SBP) $(<120$, $120-140,>140)$, physical activities ( $>60$ minutes, $60-120$ minutes, $>120$ minutes) and no. of children $(1-2,>2)$ are considered as outcomes variables.

Bivariate analysis is used to test the association between the categorical variables by applying the chi square test. But the bivariate analysis does not allow for quantification or testing the strength of the risk factors of diabetic patients among selected variables. For that reason, multiple regression analysis is used to quantify the individual effect of outcome variables (sex, age, marital status, area of residence, education level, occupation, patient's body mass index (BMI), no. of family members, Family expenses i.e. Economic status(rich, middle class, poor), Smoking habit, past family history about Diabetes (no, yes), Diastolic Blood Pressure (DBP), Systolic Blood Pressure (SBP), physical activities, and no. of children ) with diabetes as a dependent variable in different models. In this analysis, Fasting Blood Glucose (FBG) level $(6.1 \mathrm{mmol} / \mathrm{l})$ i.e. having diabetes is considered as the dependent variable.

\section{Results}

Amongst the chosen diabetic patients from BIRDEM 15095 diabetes patients aged $20-79,49.9 \%$ were male and $51.1 \%$ were female respectively.

Table 1. Frequency of education level with gender

\begin{tabular}{|c|c|c|c|}
\hline \multirow{2}{*}{$<$ SSC degree } & Sex & Number & \% of total \\
\cline { 2 - 4 } & Male & 3634 & 24.1 \\
\hline \multirow{2}{*}{ SSC/HSC/equivalent } & Female & 5709 & 37.8 \\
\cline { 2 - 4 } & Male & 2173 & 14.4 \\
\cline { 2 - 4 } Graduate/higher & Female & 1297 & 8.6 \\
\cline { 2 - 4 } & Male & 1733 & 11.5 \\
\hline \multirow{2}{*}{ Total } & Female & 549 & 3.6 \\
\hline \multirow{2}{*}{} & Male & 7540 & 50 \\
\cline { 2 - 4 } & Female & 7555 & 50 \\
\hline
\end{tabular}

Table 2. Past family history with gender frequency distribution

\begin{tabular}{|c|c|c|c|}
\hline & Sex & Number & \% of total \\
\hline \multirow{3}{*}{ No } & Male & 4610 & 30.2 \\
\cline { 2 - 4 } & Female & 4130 & 27.1 \\
\hline \multirow{2}{*}{ Yes } & Male & 3003 & 19.7 \\
\cline { 2 - 4 } & Female & 3511 & 23.0 \\
\hline \multirow{3}{*}{ Total } & Male & 7613 & 49.9 \\
\cline { 2 - 4 } & Female & 7641 & 50.1 \\
\hline
\end{tabular}

Table 3. Class in society with gender frequency distribution

\begin{tabular}{|c|c|c|c|}
\hline & Sex & Number & \% of total \\
\hline \multirow{3}{*}{ Rich } & Male & 316 & 2.1 \\
\cline { 2 - 4 } & Female & 334 & 2.2 \\
\hline \multirow{3}{*}{ Middle } & Male & 5297 & 35.7 \\
\cline { 2 - 4 } & Female & 4908 & 33.1 \\
\hline \multirow{3}{*}{ Poor } & Male & 1809 & 12.2 \\
\cline { 2 - 4 } & Female & 2184 & 14.7 \\
\hline \multirow{3}{*}{ Total } & Male & 7422 & 50 \\
\cline { 2 - 4 } & Female & 7426 & 50.0 \\
\hline
\end{tabular}


Table 4. Diastolic Blood Pressure (DBP) with gender frequency distribution

\begin{tabular}{|c|c|c|c|}
\hline \multirow{2}{*}{$<70$} & Sex & Number & \% of total \\
\hline \multirow{2}{*}{$70-90$} & Male & 1054 & 6.9 \\
\cline { 2 - 4 } & Female & 904 & 5.9 \\
\cline { 2 - 4 } & Male & 5516 & 36.2 \\
\hline \multirow{2}{*}{$>90$} & Female & 5681 & 37.3 \\
\cline { 2 - 4 } & Male & 1034 & 6.8 \\
\hline \multirow{2}{*}{ Total } & Female & 1043 & 6.8 \\
\cline { 2 - 4 } & Male & 7604 & 49.9 \\
\hline
\end{tabular}

Table 5. Systolic Blood Pressure (SBP) with gender frequency distribution

\begin{tabular}{|c|c|c|c|}
\hline SBP & Sex & Number & \% of total \\
\hline \multirow{2}{*}{$<120$} & Male & 5132 & 33.7 \\
\cline { 2 - 4 } & Female & 5082 & 33.4 \\
\hline \multirow{2}{*}{$120-140$} & Male & 2028 & 13.3 \\
\cline { 2 - 4 } & Female & 2024 & 13.3 \\
\hline \multirow{2}{*}{$>140$} & Male & 438 & 2.9 \\
\cline { 2 - 4 } & Female & 525 & 3.4 \\
\hline \multirow{2}{*}{ Total } & Male & 7598 & 49.9 \\
\cline { 2 - 4 } & Female & 7631 & 50.1 \\
\hline
\end{tabular}

Table 6. Body Mass Index (BMI) with gender frequency distribution

\begin{tabular}{|c|c|c|c|}
\hline \multirow{2}{*}{$<18.5$} & Sex & Number & \% of total \\
\hline \multirow{2}{*}{$18.5-24.99$} & Male & 526 & 3.5 \\
\cline { 2 - 4 } & Female & 461 & 3.1 \\
\cline { 2 - 4 } & Male & 4273 & 28.5 \\
\hline \multirow{2}{*}{$25-29.99$} & Female & 3290 & 21.9 \\
\cline { 2 - 4 } & Male & 2232 & 14.9 \\
\hline \multirow{2}{*}{30 and above } & Female & 2759 & 18.4 \\
\cline { 2 - 4 } & Male & 441 & 2.9 \\
\hline \multirow{2}{*}{ Total } & Female & 1028 & 6.8 \\
\cline { 2 - 4 } & Male & 7472 & 49.8 \\
\hline
\end{tabular}

Table 7. Frequency distribution with location and age range with gender

\begin{tabular}{|c|c|c|c|c|c|}
\hline & & & Sex & Number & $\%$ of total \\
\hline \multirow{6}{*}{ Rural } & \multirow{6}{*}{ Age } & \multirow{2}{*}{$<31$ years } & Male & 402 & 3.3 \\
\hline & & & Female & 711 & 5.8 \\
\hline & & \multirow{2}{*}{$\begin{array}{l}31-50 \\
\text { years }\end{array}$} & Male & 3585 & 29.2 \\
\hline & & & Female & 3682 & 30.0 \\
\hline & & \multirow{2}{*}{$>50$ years } & Male & 2291 & 18.7 \\
\hline & & & Female & 1603 & 13.1 \\
\hline \multirow{2}{*}{\multicolumn{3}{|c|}{ Total }} & Male & 6278 & 51.1 \\
\hline & & & Female & 5996 & 48.9 \\
\hline & & $<31$ vears & Male & 89 & 3.3 \\
\hline & & - 31 years & Female & 158 & 5.8 \\
\hline Urban & & $31-50$ & Male & 3585 & 29.2 \\
\hline & Age & years & Female & 3682 & 30.0 \\
\hline & & $>50$ yearc & Male & 2291 & 18.7 \\
\hline & & > 50 years & Female & 1603 & 13.1 \\
\hline & Tot: & & Male & 6278 & 51.1 \\
\hline & $10 t$ & & Female & 5996 & 48.9 \\
\hline
\end{tabular}

Table 8. Age range with the gender frequency distribution

\begin{tabular}{|c|c|c|c|c|}
\hline & & Sex & Number & $\%$ of total \\
\hline \multirow{6}{*}{ Age } & \multirow{2}{*}{$<31$ years } & Male & 510 & 3.3 \\
\hline & & Female & 911 & 6.0 \\
\hline & \multirow{2}{*}{$\begin{array}{l}31-50 \\
\text { years }\end{array}$} & Male & 4340 & 28.5 \\
\hline & & Female & 4747 & 31.2 \\
\hline & \multirow{2}{*}{$>50$ years } & Male & 2752 & 18.1 \\
\hline & & Female & 1970 & 12.9 \\
\hline \multirow{2}{*}{ Total } & \multirow{2}{*}{ Total } & Male & 7602 & 49.9 \\
\hline & & Female & 7628 & 50.1 \\
\hline
\end{tabular}

Results from the analysis show that higher percentage $(68.9 \%)$ of the diabetic patients has education levels less than SSC degree, where males were $24.1 \%$ and females were $37.8 \%$. In this study, $68.8 \%$ of the total diabetic subjects (35.7\% male, $33.1 \%$ female) were found to belong to the middle socioeconomic class; only $4.3 \%$ and $26.9 \%$ were found to belong to rich and poor socioeconomic class respectively. The highest prevalence of diabetes was observed significantly among the middle socioeconomic class and the lowest prevalence was observed significantly among the rich socioeconomic class respectively.

Increased prevalence of diabetes was observed with increased SBP. Medium DBP $(70-90 \mathrm{mmHg})$ showed a significant association with diabetes. Higher percentage (59.7\%) of Diabetic patients was observed in the age group of $31-50$ years, where male was $28.5 \%$ and female was $31.2 \%$.

\section{Identifying Confounding variables:}

Confounding is a bias introduced by the imbalanced distribution of extraneous risk factors among comparison groups. The issue of assessing confounding effects has been discussed in several papers [36-40]. It has been recognized that there are multiple risk factors for the disease of interest, type-2 diabetes. But typically we want to focus on the casual effect of only one factor 'age '; hereafter this factor is called the "exposure". In this setting, other risk factors for the disease are considered only because they might be confounders- that have substantially changed the effect estimate- rather than being of direct interest. The goal is then to study the effect of the exposure on disease, "controlling" or "adjusting" for the others.

A stepwise variable selection approach using multiple regression analysis is used in following Table 9 for assessing the confounding variables. Because Regression models are a flexible way of investigating the separate or joint effects of several risk factors for disease or ill health. These factors may include exposures and confounders of the exposure-disease relationship. In general, a regression coefficient for a factor in a model estimates the effect of an increase of one unit in that factor; if all other factors in the model stay unchanged and assuming the model assumptions 
are correct.

For assessing the relationship between the exposure 'age' and diabetics, therefore, in model-1(Table 9) only age variable is considered as a covariate. Then to study this relationship, while allowing for the effects of physical activities, model-2 is considered.
$\mathrm{FBG}=\mathrm{a}+\mathrm{b}$.age $+\mathrm{r}$
model-1
$\mathrm{FBG}=\mathrm{a}+\mathrm{b}$.age $+\mathrm{c}$.physical activities $+\mathrm{r}$ model- 2

Table 9 shows output of estimates of regression coefficient with $\mathrm{p}$ values from significance tests $(5 \%$ and $10 \%$ level of significance) from fitting model(1-15) to the data. In each test, the null hypothesis is that the true value of the coefficient is zero. If $b$ were zero, then age would have no effect on FBG. Here, the test strongly suggests that $b$ is positive i.e the unadjusted regression estimate in model-1(Table 9) indicates that there is a strong positive relationship between diabetes i.e fasting blood glucose level and age. It assumes that mean FBG increases by a fixed amount (estimated as $1.104 \mathrm{~m}$ in model-1) for every year of age. The term $r$ is a random component assumed to vary from person to person. Inclusion of this term in the model allows for the fact that people of the same age are not all the same: their individual FBG values will vary about the mean for that age (model-1). Random variation is unpredictable but, overall, it can be described by a statistical distribution. With continuous variables such as FBG, the random component is often assumed to have a Normal distribution with a mean of zero.

The effect of age diabetes remains large and highly statistically significant, when the effect of physical activities is controlled for in model-2. Additionally controlling for housewife's occupation in model-3 has little influence on the strength of the relationship between age and diabetes. Up to the model-6, when family past history, SBP, and DPB are additionally controlled, the relationship of age and diabetes remains statistically significant. Therefore, it is worth to mention that after observing all models in table-9, models 1 to 6 showed significant association with type-2 diabetics and age considering physical activities, occupation, family past history, SBP, and DPB as confounders of the relationship. Interestingly, from model-7 to model-15, result showed a negative relationship of age with type-2 diabetics but it is insignificant.

Table 9. Multiple regression: risk factors were selected stepwise in different models taking type 2 diabetes as a dependent variable

\begin{tabular}{|c|c|c|c|c|c|}
\hline Risk factors & Model 1 & Model 2 & Model3 & Model4 & Model5 \\
\hline $\begin{array}{c}\text { Age }\left(<31 \text { years }{ }^{\dagger}\right) \\
31-50 \text { years } \\
>50 \text { years }\end{array}$ & $\begin{array}{l}1.104(.165) * \\
1.405(.175) *\end{array}$ & $\begin{array}{c}.94(.174) * \\
1.21(.184) *\end{array}$ & $\begin{array}{l}.623(.200) * \\
.968(.212) *\end{array}$ & $\begin{array}{l}.615(.200) * \\
.983(.212)^{*}\end{array}$ & $\begin{array}{l}.596(.201) * \\
.952(.213) *\end{array}$ \\
\hline $\begin{array}{c}\text { Physical activities } \\
\dagger \\
\left.{ }^{\dagger}\right) \\
<60 \mathrm{~min}\end{array}$ & & $-.085(.174)$ & $-.101(.198)$ & $-.097(.198)$ & $-.094(.198)$ \\
\hline$>120 \mathrm{~min}$ & & $-0.587(.614)$ & $-1.40(.75)^{* *}$ & $-1.35(.75) * *$ & $-1.35(.75) * *$ \\
\hline $\begin{array}{c}\text { Occupation (Housewife }^{\dagger} \text { ) } \\
\text { Employed }\end{array}$ & & & $-.313(.110) *$ & $-.332(.110) *$ & $-.336(.110) *$ \\
\hline Unemployed/Pensioner & & & $.472(.196) *$ & $.408(.197) *$ & $.399(.197) *$ \\
\hline $\begin{array}{c}\text { Family past history (no }{ }^{\dagger} \text { ) } \\
\text { Yes }\end{array}$ & & & & $-.565(103) *$ & $-.560(.103) *$ \\
\hline $\begin{array}{c}\operatorname{SBP}\left(<120^{\dagger}\right) \\
120-140 \\
\end{array}$ & & & & & $-.256(.119) *$ \\
\hline$>140$ & & & & & $.030(.212)$ \\
\hline
\end{tabular}


Table 9. continued

\begin{tabular}{|c|c|c|c|c|c|}
\hline Risk factors & Model 6 & Model 7 & Model 8 & Model 9 & Model 10 \\
\hline $\begin{array}{c}\text { Age }(<31 \text { years } \\
31-50 \text { years }\end{array}$ & $.558(.20) *$ & $.245(.199)$ & $.245(.199)$ & $.251(.200)$ & $.228(.235)$ \\
\hline 50 years & $.937(.21) *$ & $.645(.21) *$ & $.631(.212) *$ & $.654(.213) *$ & $.575(.259) *$ \\
\hline $\begin{array}{c}\text { Physical activities }{ }^{\dagger}(60-120 \\
\left.\min ^{\dagger}\right) \\
<60 \mathrm{~min}\end{array}$ & $-.136(.198)$ & $-.118(.195)$ & $-.125(.195)$ & $-.139(.196)$ & $-.217(.272)$ \\
\hline$>120 \mathrm{~min}$ & $1.25(.75) * *$ & $1.012(.765)$ & $1.018(.764)$ & $.987(.764)$ & $1.953(1.50)$ \\
\hline $\begin{array}{c}\text { Occupation }_{\text {Emousewife }}^{\dagger} \text { ) } \\
\text { Employed }\end{array}$ & $-.341(.11) *$ & $-.461(.109) *$ & $-.291(.220)$ & $-.283(.221)$ & $-.051(.237)$ \\
\hline Unemployed/Pensioner & $0.37(.02) * *$ & $-.154(.197)$ & $.017(.269)$ & $.025(.270)$ & $-.101(.446)$ \\
\hline Family past history (no ${ }^{\dagger}$ ) Yes & $-.54(.103) *$ & $-.266(.10) *$ & $-.269(.103) *$ & $-.269(.103) *$ & $-.323(.124) *$ \\
\hline $\begin{array}{c}\operatorname{SBP}\left(<120^{\dagger}\right) \\
120-140\end{array}$ & $-.070(.128)$ & $.074(.126)$ & $.074(.126)$ & $.082(.126)$ & $.026(.149)$ \\
\hline$>140$ & $.366(.243)$ & $.371(.240)$ & $.328(.240)$ & $.320(.240)$ & $.557(.280) *$ \\
\hline $\begin{array}{l}\operatorname{DBP}\left(70-90^{\dagger}\right) \\
<70(\mathrm{DBP})\end{array}$ & $.648(.167) *$ & $.39(.167) *$ & $.400(.166) *$ & $.423(.167) *$ & $.613(.235) *$ \\
\hline$>90(\mathrm{DBP})$ & $-.352(.17) *$ & $-.130(.171)$ & $-.114(.171)$ & $-.111(.171)$ & $-.237(.209)$ \\
\hline $\begin{array}{c}\operatorname{BMI}\left(18.5-24^{\dagger}\right) \\
<18.5 \\
\end{array}$ & & $-3.72(.23) *$ & $-3.669(.23) *$ & $-3.703(.23) *$ & $-3.65(.296) *$ \\
\hline $24-30$ & & $1.195(.11) *$ & $1.200(.11) *$ & $1.198(.11) *$ & $1.26(.137) *$ \\
\hline $30^{+}$ & & $-1.25(.18) *$ & $-1.266(.18) *$ & $-1.275(.18) *$ & $-1.65(.19) * *$ \\
\hline Sex $\left(\right.$ Male $\left.^{\dagger}\right)$ Female & & & $.199(.219)$ & $.205(.220)$ & $.114(.312)$ \\
\hline $\begin{array}{c}\text { Family member(1-4 } \\
\left.4^{+}\right)\end{array}$ & & & & $-.088(.102)$ & $.154(.134)$ \\
\hline $\begin{array}{c}\text { number of children }\left(1-2^{\dagger}\right) \\
2^{+}\end{array}$ & & & & & $-.338(.151) *$ \\
\hline
\end{tabular}


Table 9. continued

\begin{tabular}{|c|c|c|c|c|c|}
\hline Risk factors & Model11 & Model12 & Model13 & Model14 & Model15 \\
\hline $\begin{array}{c}\text { Age }\left(<31 \text { years }{ }^{\dagger}\right) \\
31-50 \text { years }\end{array}$ & $-.281(.239)$ & $-.346(.254)$ & $-.393(.259)$ & $-.279(.26)$ & $-.335(.262)$ \\
\hline$>50$ years & $.597(.267) *$ & $.66(.282) *$ & $.709(.29) *$ & $.53(.289) * *$ & $.633(.291) *$ \\
\hline $\begin{array}{c}\text { Physical activities }{ }^{\dagger}\left(60-120 \min ^{\dagger}\right) \\
<60 \mathrm{~min}\end{array}$ & $-.223(.278)$ & $-.020(.311)$ & $.008(.313)$ & $.121(.315)$ & $.188(.316)$ \\
\hline$>120 \mathrm{~min}$ & $-.88(.1 .685)$ & $-.67(1.689)$ & $-1.36(1.818)$ & $-1.75(1.813)$ & $-1.75(1.811)$ \\
\hline $\begin{array}{c}\text { Occupation }\left(\mathrm{HW}^{\dagger}\right) \\
\text { Employed }\end{array}$ & $-.042(.246)$ & $.032(.260)$ & $.020(.265)$ & $.047(.265)$ & $.290(.280)$ \\
\hline Unemployed/Pensioner & $-.087(.468)$ & $-.014(.474)$ & $.078(.482)$ & $-.157(.265)$ & $-.039(.486)$ \\
\hline $\begin{array}{c}\text { Family past history (no }{ }^{\dagger} \text { ) } \\
\text { Yes }\end{array}$ & $-.33(.128) *$ & $-.298(.14) *$ & $-.24(.137) * *$ & $-.184(.139)$ & $-.107(.140)$ \\
\hline $\begin{array}{c}\operatorname{SBP}\left(<120^{\dagger}\right) \\
120-140(\mathrm{SBP}) \\
\end{array}$ & $-.021(.155)$ & $-.024(.160)$ & $.055(.163)$ & $.023(.164)$ & $.052(.164)$ \\
\hline$>140$ (SBP) & $0.555(.29) * *$ & $.508(.30) * *$ & $.620(.307) *$ & $.547(.309) *$ & $.591(.309) * *$ \\
\hline $\begin{array}{l}\operatorname{DBP}\left(70-90^{\dagger}\right) \\
<70(\mathrm{DBP})\end{array}$ & $.614(.247) *$ & $.51(.275) * *$ & $.607(.281) *$ & $.539(.282) * *$ & $.559(.282) *$ \\
\hline$>90(\mathrm{DBP})$ & $-.179(.216)$ & $-.095(.224)$ & $-.144(.228)$ & $-.164(.230)$ & $-.168(.230)$ \\
\hline $\begin{array}{l}\operatorname{BMI}\left(18.5-24^{\dagger}\right) \\
\quad<18.5\end{array}$ & $-3.898(.31) *$ & $-3.97(.32) *$ & $-4.02(.325) *$ & $-3.685(.33) *$ & $-3.726(.33) *$ \\
\hline $24-30$ & $1.282(.14) *$ & $1.21(.148) *$ & $1.25(.15) *$ & $1.15(.15) *$ & $1.128(.15) *$ \\
\hline $30^{+}$ & $-1.64(.195) *$ & $-1.60(.21) *$ & $-1.58(.209) *$ & $-1.43(.212) *$ & $-1.41(.212) *$ \\
\hline Sex $\left(\right.$ Male $\left.^{\dagger}\right)$ Female & $.119(.321)$ & $.160(.341)$ & $.288(.349)$ & $.246(.153)$ & $.232(.350)$ \\
\hline $\begin{array}{l}\text { Family member }\left(1-4^{\dagger}\right) \\
4^{+}\end{array}$ & $.145(.139)$ & $.105(.144)$ & $.098(.146)$ & $.060(.147)$ & $.088(.148)$ \\
\hline $\begin{array}{c}\text { number of children }\left(1-2^{\dagger}\right) \\
2^{+}\end{array}$ & $-.33(.16) *$ & $-.34(.16) *$ & $-.318(.165) *$ & $-.305(.166) * *$ & $-.214(.168)$ \\
\hline $\begin{array}{c}\text { Matital status(married }{ }^{\dagger} \text { ) } \\
\text { Unmarried }\end{array}$ & $.346(.906)$ & $.745(.990)$ & $.642(1.015)$ & $.958(1.013)$ & $1.074(1.012)$ \\
\hline $\begin{array}{c}\text { Smoking status }\left(\mathrm{No}^{\dagger}\right) \\
\text { Yes }\end{array}$ & & $.127(.381)$ & $-.007(.387)$ & $-.101(.389)$ & $-.113(.389)$ \\
\hline $\begin{array}{c}\text { Area(Rural } \\
\text { Urban }\end{array}$ & & & $32(.18) *$ & $.150(.188)$ & $.037(.191)$ \\
\hline Socioeconomic Status(Poor ${ }^{\dagger}$ ) Rich & & & & $-.864(.35) *$ & $-.62(.36) * *$ \\
\hline Middle & & & & $-1.15(.16) *$ & $-1.017(.17) *$ \\
\hline 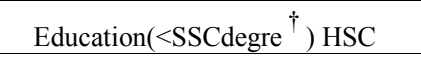 & & & & & $-.56(.194) *$ \\
\hline Graduate/higher & & & & & $-.764(.30) *$ \\
\hline
\end{tabular}

$\dagger$ Reference category, $\$$ physical activities are equivalent to walking "X” $\mathrm{min} / 24 \mathrm{~h}$ (excluded from models 1 ), $* 5 \%$ level of significance, $* * 10 \%$ level of significance

\section{Discussion}

Table 1 shows the frequency of education level with gender. Higher percentage $(68.9 \%)$ of the diabetic patients has education levels less than SSC degree, where males were $24.1 \%$ and females were $37.8 \%$. About $23 \%$ (14.4\% male, $8.6 \%$ female) and $15.1 \%$ (11.5\% male, $3.6 \%$ female) diabetic patient were found to have an educational level of SSS/HSC/equivalent and graduate/higher studies respectively.

Table 2 shows a comparison between positive and negative family history of the diabetics. Out of 15254 subjects, $(42.7 \%)$ were found to have a positive family history of diabetes, of which $19.7 \%$ was male and $23 \%$ was female. It was also found from the studies that subjects $(57.3 \%)$ have negative family history of diabetes, of which $30.2 \%$ was male and $27.1 \%$ was female.

Table 3 depicts the distribution of subjects by socioeconomic class. In this study, $68.8 \%$ of the total diabetic subjects ( $35.7 \%$ male, $33.1 \%$ female) were found to belong to the middle socioeconomic class; only $4.3 \%$ and $26.9 \%$ were found to belong to rich and poor 
socioeconomic class respectively. The highest prevalence of diabetes was observed among the middle socioeconomic class and the lowest prevalence was observed among the rich socioeconomic class respectively.

Table 4 shows the distribution by diastolic blood pressure (DBP) with gender frequency distribution. Table 5 shows the distribution of subject by systolic blood pressure (SBP). Both diastolic blood pressure (DBP) and systolic blood pressure (SBP) were investigated for their association with diabetes. Increased prevalence of diabetes was observed with increased SBP. Medium DBP $(70-90 \mathrm{mmHg})$ showed a significant association with diabetes, the percentage being which was found $73.5 \%$ (where $36.2 \%$ male, $37.3 \%$ female) whereas the percentages were found to be $12.8 \%$ and $13.6 \%$ for the group of $<70 \mathrm{mmHg}$ and $>90 \mathrm{mmHg}$ respectively. On the other hand, a comparison between groups of SBP $<120 \mathrm{mmHg}, 120-140 \mathrm{mmHg}$ and $>140 \mathrm{mmHg}$, showed a higher prevalence in the group $<120 \mathrm{mmHg}(67.1 \%)$, as compared to the groups of $>140 \mathrm{mmHg}(6.3 \%)$ and $120-140$ $\mathrm{mmHg}(26.6 \%)$.

Table 6 shows the distribution subjects by index (BMI). In the subjects under study $50.4 \%$ (male $28.5 \%$, female $21.9 \%$ ) diabetics had BMI 18.5-24.9, whereas $6.6 \%$ diabetics had BMI <18.5, 33.3\% had BMI 25-29.99 and $9.7 \%$ had $\mathrm{BMI}>30$.

Table 7 represents the percentage distribution of diabetic patients by living area. Diabetes was found higher (59.2\%) in both urban and rural populations for age ranges $31-50$ years. There were very few diabetic patients $(9.2 \%)$ in the age range $<31$ years, having $3.3 \%$ male and $5.8 \%$ female population.

Table 8 shows the age range with the gender frequency distribution. Higher percentage (59.7\%) of Diabetic patients was observed in the age group of 31-50 years, where male was $28.5 \%$ and female was $31.2 \%$. About $31.0 \%$ ( $18.1 \%$ male, female $12.9 \%$ ) and $9.3 \%$ (male $3.3 \%$, female $6.0 \%$ ) diabetics were found in the age group of $>50$ years and $<31$ years respectively.

The result of association between type 2 diabetes among some selected socio-economic, demographic, and health consciousness related characteristics of diabetic patients have been demonstrated in Table 9. Table 9 reveals the fifteen numbers of models created by controlling one by one factors to get the idea about confounding. In model-1(Table -9) it was found that the type-2 diabetic patients are significantly belonged in the middle (31-50 years) and older age group ( $>50$ years). It was also observed in other studies that prevalence of diabetes was associated with increasing age [35].From the Table 9 in model -3 , it is also found that age, controlling physical activities and occupation of the respondents, is significantly associated with the type 2 diabetes of diabetic patients. So, here occupation has been revealed as a confounding. Not only that, physical activities more than 120 minutes is also significantly associated with type- 2 diabetes. It was identified that unemployed/pensioner and past family history are significantly associated with an increase in diabetes. Interestingly, from model-10 to model-14, more than two numbers of children showed a negative relationship with type-2 diabetics.

After observing all models in Table 9, sex, marital status, number of family members, smoking status was not found significant association with type- 2 diabetics for none of the models. In addition, occupation, family past history, physical activities, SBP, and DBP can be considered as potential confounders because these factors confounded the effect of the strength of the relationship between diabetes and age.

\section{Acknowledgements}

We acknowledge gratefully that the study is supported by the HEQEP sub-project 3293, University Grants Commission of Bangladesh and the World Bank. We are very grateful to Helal Uddin Ahmed (Associate Professor and Director Southeast University) and Parvin Akter Khanam (Senior Research Officer, Department of Epidemiology \& Biostatistics, BIRDEM) for their valuable advices.

\section{REFERENCES}

[1] Akhter A, Fatema K, Afroz A, Bhowmik B, Ali L, Hussain A. Prevalence of Diabetes Mellitus and its Associated Risk Indicators in a Rural Bangladeshi Population. The Open Diabetes Journal. 2011; 4: 6-13.

[2] Knowler WC, Pettitt DJ, Savage PJ, Bennett PH. Diabetes incidence in Pima Indians: Contributions of obesity and parental diabetes. Am J Epidemiol. 1981; 113: 144-156.

[3] OSullivan JB.Body weight and subsequent diabetes mellitus. JAMA. 1982; 248: 949-952.

[4] Hansen BC, Bodkin NL.Primary prevention of diabetes mellitus by prevention of obesity in monkeys. Diabetes .1993; 42:1809-1814.

[5] Long SD, OBrien K, MacDonald KG, Leggett-Frazier N, Swanson MS, Pories WJ,Caro JF. Weight loss in severely obese subjects prevents the progression of impaired glucose tolerance to type II diabetes. Diabetes Care. 1994; $17: 372-375$.

[6] Manson J, Rimm E, Stampfer MJ, Colditz GA, Willet W, Krolewski A.Physical activity And incidence of non-insulin-dependent diabetes mellitus in women. Lancet. $1991 ; 338: 774-778$.

[7] Helmrich S, Ragland D, Leung W, Paewnbarger R. Activity and reduced occurrence of non-insulin-dependent diabetes mellitus. N Engl J Med.1991; 325:147-152.

[8] Mayer-Davis JE, DAgostino R, Karter AJ, Ha ner SM, Rewers MJ, Saad M. Intensity and amount of physical activity in relation to insulin sensitivity: the Insulin Resistance at herosclerosis study. JAMA.1998; 279: 669-674. 
[9] Field C, Ryan E, Thomas A, Clandinin M. Dietary fat and the diabetic state alter insulin binding and the fatty ACYL composition of the adipocyte plasma membrane. J Biochem. $1988 ; 253: 417-424$.

[10] Marshall JA, Hoag S, Shetterly S, Hamman R: Dietary fat predicts conversion from impaired glucose tolerance to NIDDM. Diabetes Care. 1994;17:50-55.

[11] Mayer E, Newman B, Quesenberry C, Selby V: Usual dietary fat intake and insulin concentration in healthy women twins. Diabetes Care. 1993; 16:1459-1469.

[12] Riccardi G, Rivellese AA: Effects of dietary fiber and carbohydrate on glucose and lipoprotein metabolism in diabetic patients. Diabetes Care. 1991;14:1115-1131.

[13] Salmeron J, Manson JE, Stampfer MJ, Colditz GA, Wing AL, Willet WC: Dietaryber, glycemicload, and risk of noninsulin dependent diabetes mellitus in women. JAMA.1997; 277:472-477.

[14] Debra Manzella RN, 2010, Top 7 Risk Factors for Type 2 Diabetes ,Retrieved 3rd March, 2013 from http://diabetes.about.com/od/symptomsdiagnosis/tp/riskfacto rs.htm

[15] Gress TW, Nieto FJ, Shahar E, Wo_ord MR, Brancati FL. Hypertension and anti hypertensive therapy as risk factors for type 2 diabetes mellitus. Atherosclerosis Risk in Communities Study.N Engl J Med. 2000; 342(13):905-12.

[16] Garcia MJ, McNamara PM, Gordon T, Kannel WB. Morbidity and mortality in diabetics in the Framingham population sixteen year follow up study. Diabetes. 1974; 23: 105.

[17] Elia, Marinos. Obesity in the Elderly. Obesity Research. 2001; 9( 4): 244-248.

[18] Albu J, Raja Khan N. The management of the obese diabetic patient. Journal of Primary Care. 2003; 30 (2).

[19] Schienkiewitz A, Matthias B Schulze, Ho mann K, Kroke A,Boeing H. Body mass index history and risk of type 2 diabetes: results from the European Prospective Investigation into Cancer and Nutrition (EPIC) Potsdam Study. The American Journal of Clinical Nutrition. 2006; 84:427-33.

[20] Chakma K, Banik RG, Sikdar D. Risk Factors for Developing Diabetes Mellitus amongst Diabetic Patients Attending at the Chittagong Diabetes Hospital Complex. Bangladesh Journal of Nutrition. 2010; 22-23:31-40

[21] Sayeed MA, Hussain MZ, Rumi MA, Banu A, Khan AKA. Effect of Socioeconomic Risk Factors on the Di erence in Prevalence of Diabetes Between Rural and Urban Populations in Bangladesh. Diabetes Care. 1997; 20(4): 551-555.

[22] Wild S, Roglic G, Green A. Global Prevalence of Diabetes Estimates for the year 2000 and projections for 2030. Diabetes Care. 2004; 27:1047-1053.

[23] Connolly V ,Unwin N,Sherrif P,Bilous R,Kelly W.Diabetes prevalence and socioeconomic status: a population based study showing increased prevalence of type 2 diabetes mellitus in deprived areas.J Epidemiol Community Health. 2000; 54:173-177

[24] Sayeed MA,Mahtab H,Khanam PA, Ahsan KA, Banu A, Rashid AN.Diabetes and impaired fasting glycemia in the tribes of Khagrachari hill tracts of Bangladesh. Diabetes Care. 2004; 27: 1054-1059.
[25] Katulanda P,Rathnapala DAV,Sherif R, Matthews DR.Province and ethnic specific prevalence of diabetes among Sri Lankan adults. Sri Lanka Journal of Diabetes Endocrinology and Metabolism. 2011; 1: 2-7

[26] Stern MP, Gaskill SP, Hazuda HP, Gardner LI, Haffner SM. Does obesity explain excess prevalence of diabetes among Mexican Americans? Results of the San Antonio Heart Study. Diabetologia.1983; 24:272-277.

[27] Trevino, R.P., Pugh, J.A., Hernandez, A.E., Menchaca, V.D., Ramirez, R.R., Mendoza, M. Bienstar (A diabetes risk-factor prevention program) . Journal of School Health. 1998; 68:62-67

[28] Neufeld D, Chen YDI, Ra_el LJ, Vadheim CM, Landon C. Early presentation of type 2 diabetes in Mexican-American youth. Diabetes Care. 1998; 21: 80-86.

[29] Choi BCK, Shi F. Risk factors for diabetes mellitus by age and sex: results of the National Population Health Survey. Diabetologia. 2001; 44: 1221-1231.

[30] Islam R,Rahman O. The Risk Factors of Type 2 Diabetic Patients Attending Rajshahi Diabetes Association, Rajshahi, Bangladesh and Its Primary Prevention. Food and Public Health. 2012; 2(2): 5-11

[31] Rimm EB,Manson JE, Stampfer MJ , Colditz GA, Willett WC, Rosner B,Hennekens CH,Speizer FE. Cigarette smoking and the risk of diabetes in women. American Journal of Public Health. 1993; 83( 2):211-214.

[32] Rimm EB,Chan J,Stampfer MJ, Colditz GA, Willett WC. Prospective study of cigarette smoking, alcohol use, and the risk of diabetes in men. BMJ. 1995; 310 (6979): 555-559.

[33] Rahim MA, Vaaler S, Ali SMK, Khan AKA,Hussain A, Nahar Q. Prevalence of type 2 diabetes in urban slums of Dhaka, Bangladesh. Bangladesh Medical Research Council Bulletin. 2004; 30(2): 60-70.

[34] Hussain A, Vaaler S, Sayeed MA,Mahtab H, Ali SMK, Khan AKA. Type 2 diabetes and impaired fasting blood glucose in rural Bangladesh: a population-based study. The European Journal of Public Health. 2007; 17(3):291-296.

[35] Ramachandran A, Snehalatha C, and Vijay V. Temporal changes in prevalence of type 2 diabetes and impaired glucose tolerance in urban southern India. Diabetes Research and Clinical Practice. 2002; 58, 55-60.

[36] Greenland, S., and J. M. Robins. 1986. Identifiability, exchangeability, and epidemiological confounding. International Journal of Epidemiology 15: 413-419.

[37] Grayson, D. A. 1987. Confounding confounding. American Journal of Epidemiology 126: 546-553.

[38] Weinberg, C. R. 1993. Toward a clearer definition of confounding. American Journal of Epidemiology 137: 1-8.

[39] Sturmer, T., S. Schneeweiss, J. Avorn, and R. J. Glynn. 2005. Adjusting effect estimates for unmeasured confounding with validation data using propensity score calibration. American Journal of Epidemiology 162: 279-289.

[40] Wang, Z. 2000. sbe27: Assessing confounding e ects in epidemiological studies. Stata Technical Bulletin 49: 12-15. Reprinted in Stata Technical Bulletin Reprints, vol. 9, pp. 134 (138. College Station, TX: Stata Press) 